\title{
Study on Effect of Carbonation on the Properties of Fruit Juices
}

\author{
Nikhil D. Solanke ${ }^{1 *}$, Shravasti Sontakke ${ }^{2}$ and Sachin Verma ${ }^{3}$ \\ ${ }^{1}$ Department of Food Science and Technology, Jagdish Prasad Jhabermal Tibrewala University \\ Jhunjhunu, Rajasthan, India \\ ${ }^{2}$ Department of Food Science and Technology, National Institute of Food Technology \\ Entrepreneurship and Management, Kundli, Haryana, India \\ *Corresponding author
}

\section{A B S T R A C T}

Keywords

Carbonation, $\mathrm{CO}_{2}$, Temperature, Pressure, $\mathrm{NaOH}$

Article Info

Accepted:

20 March 2017

Available Online:

10 April 2017
The effect of carbonation on finished product of fruit juice was estimated. The effect of temperature on solubility of $\mathrm{CO}_{2}$ shows that gas had more solubility at low temperatures and the solubility decrease with increase in temperature, where the effect of pressure on the dissolubility of $\mathrm{CO}_{2}$, as increase in concentration of gas in liquid with increase in pressure as more amount of $\mathrm{NaOH}$ is being used in titration with increase in pressure.

\section{Introduction}

Carbonation of fruit juices can also have a great scope in the future as carbonated soft drinks are very popular among youth and are known for their thrust quenching and refreshing properties but they lack the nutritional value. But the fruit juices which contain all the nourishing properties and the goodness of the fruit if they are carbonated then they can be a popular choice among youth for fruit drinks. Carbonated fruit based beverage is a new concept which provides nutritional elements of the fruit along with natural pigments and flavor in addition to carbonation effects.

Carbonation means dissolution of carbon dioxide in liquid. The process of carbonation involves carbon dioxide under high pressure.
Club soda is one of the most popular carbonated drinks in carbonated beverages. Carbon dioxide is dissolved in the liquid under high pressure. Due to this high pressure when a carbonated bottle is opened that its pressure is reduced carbon dioxide comes out of the liquid in the form of small bubbles which causes the solution to become effervescent. The carbonated beverages taste good because of the tingling affect produced by them. The sensations elicited by carbonated drinks are either of mechanical origin, due to the bursting $\mathrm{CO}_{2}$ bubbles stimulating mechanoreceptors on the tongue, or of chemogenic origin by formation of carbonic acid $\left(\mathrm{H}_{2} \mathrm{CO}_{3}\right)$ in a reaction catalyzed by carbonic anhydrase, which stimulates polymodal nociceptors in the oral cavity 
(Dessirier et al., 2000). The concentration level of $\mathrm{CO}_{2}$ is 4 to 5 times greater than saturation equilibrium value and it depend on existing gas-liquid interfaces (Lubetkin and Blackwell, 1988; Wilt, 1986). Bubbles also have a sensory impact on the beverage, where $\mathrm{CO}_{2}$ gives impinge upon the tongue and increasing the "tingling', sensation (Barker et al., 2002a, 2002b).

The objective of this study to examine the temperature and pressure on $\mathrm{CO}_{2}$ and study the effect of temperature on solubility of $\mathrm{CO}_{2}$ and effect of pressure on the dissolubility $\mathrm{CO}_{2}$.

\section{Materials and Methods}

Most of beverages such as fruit based drinks, sweetened aerated water or carbonated drinks and sometimes nonalcoholic beer, etc. Most of the carbonated drinks contain synthetic colour and flavouring components which are suspected to be allergenic (Taylor, 1982). Inclusion of fruit juice in the soft drinks not only imparts characteristic colour and flavour but also provides some nutrients.

The demand for soft drinks is increasing every year. This trend can be exploited by developing nutrient enriched carbonated fruit based beverages. The growing health consciousness of consumers has made the industry to introduce a variety of beverages (Dwivedi, 2009).

\section{Procurement of raw material}

Malta which is a variety of orange was procured from International fruit market Aazadpur, New Delhi. The fruits were taken in a single lot to get rid of any varietal differences. Then the fruits were cleaned, dried and stored in refrigerated conditions in the cold room.

Juice extraction
Malta was peeled with hand and juice was extracted with hand operated juicer then juice was filtered with muslin cloth and the juice was then filled in previously sterilized bottles and the juice was then pasteurized at $85^{\circ} \mathrm{C}$ for 10 minutes in bottles then it was cooled and then sorted at temperature in the range of 1$4^{\circ} \mathrm{C}$

\section{Process of carbonation}

We can carbonate almost anything with the help of this assembly from fruits, fruit juices, water, yogurt etc. This is a very simple process to start the process first fit the assembly properly after that put the material to be carbonated in to the carbonation bottle. Squeeze the bottle to make space for the $\mathrm{CO}_{2}$ to fill in then put the carbonation cap in to the bottle. Then open the valve of the cylinder adjust the pressure of the gas required with the help of the regulator and carbonate the sample by connecting the chuck to the valve of the carbonation cap and you are ready with the carbonated material store it under refrigerated conditions for letting the $\mathrm{CO}_{2}$ to dissolve in sample and serve chilled. The major thing to keep in mind during carbonation is the temperature of the material to be carbonated and the pressure of the gas as both these factors play an important role in the dissolution of $\mathrm{CO}_{2}$ in the liquid. Solubility of $\mathrm{CO}_{2}$ depends on the temperature of the material to be carbonated and the pressure of the gas above the liquid. So to understand all these and the effect of different parameters on the process of carbonation first juice was extracted from malta fruit and different variations of juice with different TSS values were made and they were carbonated at changing temperature and pressure and their combined effect was studied on the quality and taste of juice and after that the juice was carbonated at that temperature and pressure which suits best for the malta juice.

Equipment used for the carbonation 
Carbonation rig with a regulator was used for the carbonation of malta fruit juice. The equipment consists of the following things:

$\mathrm{CO}_{2}$ cylinder

Gas regulator

Pipe

Carbonating caps

Dual head tire air chuck

\section{$\mathrm{CO}_{2}$ cylinder}

$\mathrm{CO}_{2}$ cylinders contain $\mathrm{CO}_{2}$ under high pressure. $\mathrm{CO}_{2}$ is sold commercially in steel and aluminum tanks of varying sizes. The tank has a mild steel and it capacity is $3 \mathrm{~L}$. The $\mathrm{CO}_{2}$ is stored in liquid form inside the tank. Under high pressure $\mathrm{CO}_{2}$ is in liquid state but as the pressure is reduced it comes to the gaseous state.

\section{Regulator}

To use the cylinder we need a regulator which can regulate the pressure of gas and bring it down to working pressure. It is easily available in the market. The regulator used in this study contains two gauges one which shows the cylinder's pressure and the other one which shows the pressure of the gas that are coming out of the cylinder. The regulator that is used in this study measures the gas pressure in $\mathrm{KG} / \mathrm{cm}^{2}$

\section{Pipe}

To direct the gas to the bottle we need a PVC pipe which is connected to the regulator and which direct the gas under working pressure to the bottle containing the juice. The must be able to hold the pressure of the gas

\section{Carbonation caps}

The carbonation cap was made with the help of bike tire valve. It was made by with a hole in the $1 \mathrm{~L}$ plastic bottle cap and the valve was adjusted in it. The major advantage of it is that it does not allow the gas from inside of the bottle to come out.

\section{Dual head tire air chuck}

This air chuck is connected to the other end of the tube. As the carbonation cap which contains the tire valve will not let the gas in without this so we need a tire chuck to introduce the gas into the liquid through the carbonation cap.

\section{Measurement of concentration of $\mathrm{CO}_{2}$ in juice}

The dissolution rate of $\mathrm{CO}_{2}$ was calculated with a simple experiment. As carbon dioxide gas is dissolved in water its acidity increase and it becomes more acidic. The amount of $\mathrm{CO}_{2}$ in solution was measured indirectly by measuring the amount of acidity with a technique called titration.

$\mathrm{CO}_{2}(\mathrm{aq})+\mathrm{NaOH}(\mathrm{aq}) \rightarrow \mathrm{NaHCO}_{3}(\mathrm{aq}) 28$

When all the carbon dioxide is consumed by $\mathrm{NaOH}$, the solution will no longer be acidic and the phenolphthalein indicator used to turn into pink. The moles of $\mathrm{CO}_{2}$ present are in a 1:1 ratio with the moles of sodium hydroxide titrated.

1. Approximately $40 \mathrm{ml}$ of $0.100 \mathrm{M} \mathrm{NaOH}$ was obtained in a small, clean beaker.

2. A $25 \mathrm{ml}$ burette was rinsed with about $5 \mathrm{ml}$ of distilled water and drain into sink. Then, rinsed and drained with about $5 \mathrm{ml}$ of the sodium hydroxide solution. Allow some of the solution to flow through the tip.

3. Carefully, the burette was filled with standard $\mathrm{NaOH}$ until the bottom of the meniscus at $0.0 \mathrm{ml}$ mark.

4. A graduate was used to add exactly $25.0 \mathrm{ml}$ of carbonated juice to a clean conical flask. Stirred briefly with a clean stirring rod to remove "extra" carbon dioxide due to supersaturation. Measure and record the 
temperature of the soda solution, and then 2 to 3 drops of the indicator phenolphthalein was added to the flask.

5. The soda carbonated juice was carefully titrated with sodium hydroxide solution while gently swirling the flask to mix the solutions. Continued until the pink color does not disappear after swirling. This is called the end point of the titration. Record the volume sodium hydroxide solution used to the nearest $0.1 \mathrm{ml}$.

6. Steps 4 and 5 repeated using a clean flask for the different samples of juices which are maintained at different temperatures. Don't forget to add the indicator. Be sure to record the temperature of the soda water just prior to the titration and the volume of $\mathrm{NaOH}$ used during this second titration.

\section{Results and Discussion}

\section{Effect of temperature on the solubility of $\mathrm{CO}_{2}$}

To study the effect of temperature on the solubility of gas a sample of fresh juice was taken and it was carbonated at different temperatures. Four lots were made out of the sample namely L1, L2, L3, L4 and carbonation was done at different temperatures for each lot:

L1 was carbonated at $5^{\circ} \mathrm{C}$

$\mathrm{L} 2$ was carbonated at $10^{\circ} \mathrm{C}$

$\mathrm{L} 3$ was carbonated at $15^{\circ} \mathrm{C}$

$\mathrm{L} 4$ was carbonated at $20^{\circ} \mathrm{C}$

Molarity of $\mathrm{CO}_{2}$ in the carbonated juice at all four temperatures is calculated with the help of a stoichiometry solution

Molarity of $\mathrm{CO}_{2}$ in soda $=($ Vol. of $\mathrm{NaOH}$ in L) $x$ (Molarity of $\mathrm{NaOH}$ ) $x$ (Mole ratio $\left.\mathrm{CO}_{2} / \mathrm{NaOH}\right) \times(1 / \mathrm{Vol}$ soda in Lit. $)$

So with the help of the equation the moles of $\mathrm{CO}_{2}$ in carbonated malta beverage can be calculated so the result comes out to be
Average Moles of $\mathrm{CO}_{2}$ at temperature $5^{\circ} \mathrm{C}$ $=0.12 \mathrm{moles}$

Average moles of $\mathrm{CO}_{2}$ at temperature $10^{\circ} \mathrm{C}$ $=0.11 \mathrm{moles}$

Average moles of $\mathrm{CO}_{2}$ at temperature $15^{\circ} \mathrm{C}$ $=0.10 \mathrm{moles}$

Average moles of $\mathrm{CO}_{2}$ at temperature $20^{\circ} \mathrm{C}$ $=0.09$. moles

\section{Analysis results}

From the above experiment it is clear that gas has more solubility at low temperatures and the solubility decrease with increase in temperature. As more $\mathrm{NaOH}$ was used at juices with low temperature as compared to the juices with high temperature. The reason for this gas solubility relationship with temperature is very similar to the reason that vapor pressure increases with temperature. Increased temperature causes an increase in kinetic energy. The higher kinetic energy causes more motion in molecules which break intermolecular bonds and escape from solution. This can also be proved with the help of Le Chatelier's principle. As there is equilibrium maintained in the carbonated juice bottle between the dissolved gas and undissolved gas. The gas molecules in a liquid are dissolved by the process of dissolution. During this process heat is evolved. According to Le Chatelier's Principle which states that when the equilibrium of as system is disturbed, the system readjusts itself in such way that the effect that has caused the change in equilibrium is countered. So, as we know that dissolution is an exothermic process, the solubility should decrease with increase in temperature to validate Le Chatelier's Principle.

Effect of pressure on the dissolubility of $\mathrm{CO}_{2}$

Pressure is an another important parameter which plays an important role in the dissolution of gas so to understand the effect 
of pressure on the dissolubility already cooled juice was carbonated at different pressure in the pressure range of $2-6 \mathrm{~kg} / \mathrm{cm}^{2}$. The rate of dissolution was analyzed with the help of the same experiment which is done for temperature analysis that is titration. Four lots were prepared and were carbonated at different pressures.
$\mathrm{P}_{1}$ was carbonated at $3 \mathrm{Kg} / \mathrm{cm}^{2}$

$\mathrm{P}_{2}$ was carbonated at $4 \mathrm{Kg} / \mathrm{cm}^{2}$

$\mathrm{P}_{3}$ was carbonated at $5 \mathrm{Kg} / \mathrm{cm}^{2}$

$\mathrm{P}_{4}$ was carbonated at $6 \mathrm{Kg} / \mathrm{cm}^{2}$

Molarity of $\mathrm{CO}_{2}$ in the carbonated juice at all four temperatures is calculated with the help of a stoichiometry solution.

Table.1 ANOVA results for the volume of $\mathrm{NaOH}$ used at different temperatures

\begin{tabular}{|c|c|c|c|c|c|}
\hline Temp of juice & Trial & $\begin{array}{l}\text { NaOH titrated in } \\
\text { ml }\end{array}$ & Mean \pm S. D & $\begin{array}{l}\text { Standard } \\
\text { error }\end{array}$ & P-value \\
\hline $\mathrm{L} 15^{\circ} \mathrm{C}$ & 1 & 30 & \multirow{3}{*}{$30.16 \pm 0.15$} & \multirow{3}{*}{0.115} & \multirow{3}{*}{$<0.0001$} \\
\hline & 2 & 30.3 & & & \\
\hline & 3 & 30.2 & & & \\
\hline $\mathrm{L} 210^{\circ} \mathrm{C}$ & 1 & 28.8 & \multirow{3}{*}{$28.63 \pm 0.15$} & \multirow{3}{*}{0.163} & \multirow{3}{*}{$<0.0001$} \\
\hline & 2 & 28.6 & & & \\
\hline & 3 & 28.5 & & & \\
\hline \multirow[t]{3}{*}{$\mathrm{L} 315^{\circ} \mathrm{C}$} & 1 & 26.8 & \multirow{3}{*}{$26.5 \pm 0.26$} & \multirow{3}{*}{0.163} & \multirow{3}{*}{$<0.0001$} \\
\hline & 2 & 26.4 & & & \\
\hline & 3 & 26.3 & & & \\
\hline \multirow[t]{3}{*}{$\mathrm{L} 420^{\circ} \mathrm{C}$} & 1 & 24.8 & \multirow{3}{*}{$24.56 \pm 0.20$} & \multirow{3}{*}{0.163} & \multirow{3}{*}{$<0.0001$} \\
\hline & 2 & 24.5 & & & \\
\hline & 3 & 24.4 & & & \\
\hline
\end{tabular}

ANOVA analysis of volume of $\mathrm{NaOH}$ used on titration of carbonated juice on increasing temperature (mean \pm standard deviation, $\mathrm{n}=3$ )

Table.2 ANOVA results for the amount of $\mathrm{NaOH}$ used at different pressures

\begin{tabular}{|c|c|c|c|c|c|}
\hline $\begin{array}{c}\text { Pressure of } \\
\mathrm{CO}_{2}\end{array}$ & Trial & $\begin{array}{l}\text { NaOH titrated } \\
\text { in } \mathrm{ml}\end{array}$ & Mean \pm S.D & $\begin{array}{c}\text { Standard } \\
\text { error }\end{array}$ & P-value \\
\hline $\mathrm{P} 13 \mathrm{Kg} / \mathrm{cm}^{2}$ & 1 & 22.7 & \multirow{3}{*}{$22.53 \pm 0.15$} & \multirow{3}{*}{0.128} & \multirow{3}{*}{$<0.0001$} \\
\hline & 2 & 22.5 & & & \\
\hline & 3 & 22.4 & & & \\
\hline $\mathrm{P} 24 \mathrm{Kg} / \mathrm{cm}^{2}$ & 1 & 24.5 & \multirow{3}{*}{$24.56 \pm 0.20$} & \multirow{3}{*}{0.181} & \multirow{3}{*}{$<0.0001$} \\
\hline & 2 & 24.8 & & & \\
\hline & 3 & 24.4 & & & \\
\hline P3 $5 \mathrm{Kg} / \mathrm{cm}^{2}$ & 1 & 27.8 & \multirow{3}{*}{$27.5 \pm 0.3$} & \multirow{3}{*}{0.181} & \multirow{3}{*}{$<0.0001$} \\
\hline & 2 & 27.2 & & & \\
\hline & 3 & 27.5 & & & \\
\hline $\mathrm{P} 46 \mathrm{Kg} / \mathrm{cm}^{2}$ & 1 & 31 & \multirow{3}{*}{$30.8 \pm 0.2$} & \multirow{3}{*}{0.181} & \multirow{3}{*}{$<0.0001$} \\
\hline & 2 & 30.6 & & & \\
\hline & & 30.8 & & & \\
\hline
\end{tabular}

ANOVA analysis of volume of $\mathrm{NaOH}$ used on titration of carbonated juice on increasing pressure (mean \pm standard deviation, $\mathrm{n}=3$ ) 

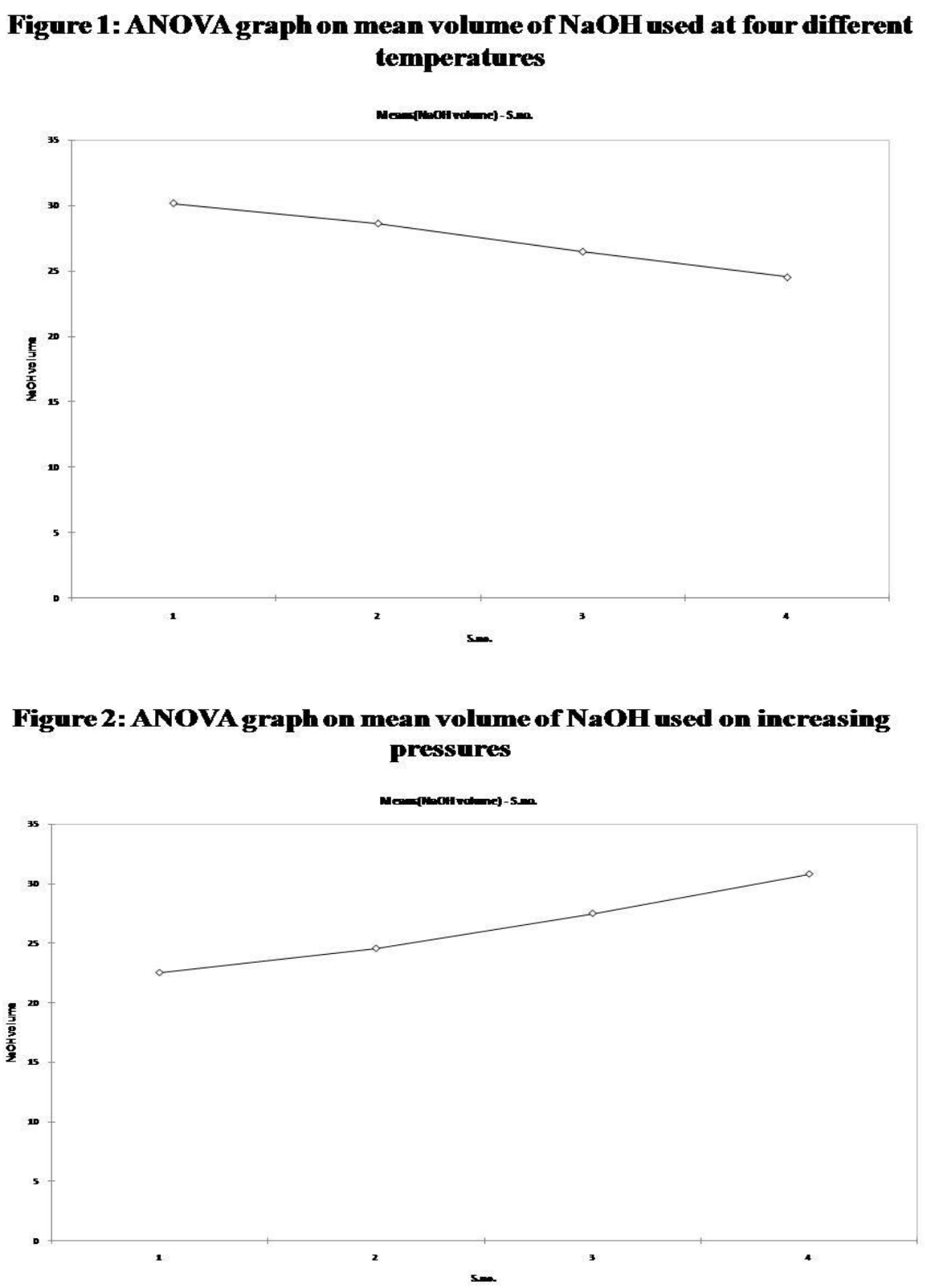

Molarity of $\mathrm{CO}_{2}$ in soda $=($ Volume of $\mathrm{NaOH}$ in $\mathrm{L}$ ) $x$ (molarity of $\mathrm{NaOH}) \times$ (mole ratio $\left.\mathrm{CO}_{2} / \mathrm{NaOH}\right) \times(1 /$ volume soda in $\mathrm{L})$

So with the help of the equation the moles of $\mathrm{CO}_{2}$ in carbonated malta beverage can be calculated so the result comes out to be

1. Average Moles of $\mathrm{CO}_{2}$ at $3 \mathrm{~kg} / \mathrm{cm}^{2}=$ 0.090 moles

2. Average moles of $\mathrm{CO}_{2}$ at $4 \mathrm{~kg} / \mathrm{cm}^{2}=$ 0.098 moles
3. Average moles of $\mathrm{CO}_{2}$ at $5 \mathrm{~kg} / \mathrm{cm}^{2}=$ 0.11 moles

4. Average moles of $\mathrm{CO}_{2}$ at $6 \mathrm{~kg} / \mathrm{cm}^{2}=$ 0.12 moles

\section{Analysis report}

It is clear from the above calculations that there is an increase in concentration of gas in liquid with increase in pressure as more amount of $\mathrm{NaOH}$ is being used in titration with increase in pressure. We increase the pressure of the system by compressing the gas molecules present 
above the solution. As a result of increase in pressure the gases molecules will now be concentrated in a smaller volume. This will result in an increase in the number of gas molecules per unit volume available above the solution. Since the number of gas molecules present above the solution has increased, the rate with which the gas molecules will be entering the solution will also increase. The end result is an increase in amount of gas molecules in the solution until a new equilibrium point is attained. Thus the solubility of gases increases with increase in the pressure of a gas above the solution.

Henry's Law gives a quantitative relation between pressure and gas solubility in a liquid. It states that the solubility of a gas in a liquid is directly proportional to the partial pressure of the gas present above the surface of liquid or solution. The most general way of using Henry's Law is that the partial pressure of a gas above a solution is proportional to the mole fraction of the gas in the solution.

$\mathrm{P}=\mathrm{KHx}$

Where, $p=$ partial pressure of the gas $\mathrm{x}=$ mole fraction of the gas in solution $\mathrm{KH}=$ Henry's law constant

In conclusion the present study related to carbonated beverage can be prepared from malta fruit by maintaining the temperature of fruit juice and pressure of gas inside the liquid. On the basis of above results and discussions it was found that fruit juice can easily be carbonated just with the help of a $\mathrm{CO}_{2}$ cylinder all be need is a carbonation cap just to keep the $\mathrm{CO}_{2}$ inside the bottle. $\mathrm{CO}_{2}$ dissolves best at low temperature and high pressure; these are most favorable conditions for the carbonation of fruit juices.

\section{References}

Barker, G. S., Jefferson, B., and Judd, S. J. (2002a). The control of bubble size in carbonated beverages. Chemical Engineering Science. 57, 565-573.

Barker,G.S., Jefferson, B., and Judd, S. J. (2002b). Domestic carbonation process optimisation. Journal of Food Engineering. 52, 405-412.

Dessirier, J.M., Simons, C., Carstens, M. I., O. Mahony, M., and Carstens, E. (2000). Psychophysical and neurobiological evidence that the oral sensation elicited by carbonated water is of chemogenic origin. Chemical Senses. 25, 277-284.

Lubetkin, S., and Blackwell, M. (1988). The nucleation of bubbles in supersaturated solutions. Journal of Colloid and Interface Science. 26, 610-615.

Mridula Dwivedi, (2009). Online destination image of India: a consumer based perspective. International Journal of Contemporary Hospitality Management. Vol. 21 Iss: 2, pp.226 - 232

Taylor, S. E. (1982). The availability bias in social perception and interaction. In D. Kahneman, P. Slovic and A. Tversky (Eds.) Judgment under uncertainty: Heuristics and biases (pp. 190-200). New York: Cambridge University Press.

Wilt, P. M. (1986). Nucleation rates and bubble stability in water carbon dioxide solutions. Journal of Colloid and Interface Science. 112, 530-538.

\section{How to cite this article:}

Nikhil D. Solanke, Shravasti Sontakke and Sachin Verma. 2017. Study on Effect of Carbonation on the Properties of Fruit Juices. Int.J.Curr.Microbiol.App.Sci. 6(4): 2426-2432.

doi: https://doi.org/10.20546/ijcmas.2017.604.283 